\title{
Resveratrol causes arrest in the S-phase prior to Fas-independent apoptosis in CEM-C7H2 acute leukemia cells
}

\author{
D Bernhard ${ }^{1,2}$, I Tinhofer ${ }^{3}, \mathrm{M} \mathrm{Tonko}^{2}$, H Hübl ${ }^{1}$, \\ MJ Ausserlechner ${ }^{2}$, R Greil $^{3}$, R Kofler ${ }^{2}$ and A Csordas ${ }^{\star, 1}$ \\ 1 Institute of Medical Chemistry and Biochemistry, University of Innsbruck, \\ A-6020 Innsbruck, Austria \\ 2 Institute for General and Experimental Pathology, Division of Molecular \\ Pathophysiology, University of Innsbruck, A-6020 Innsbruck, Austria \\ ${ }^{3}$ Laboratory of Molecular Cytology, Division of Hematology and Oncology, \\ Department of Internal Medicine, University of Innsbruck, A-6020 Innsbruck, \\ Austria \\ * Corresponding author: A Csordas, Institute of Medical Chemistry and \\ Biochemistry, University of Innsbruck, Fritz-Pregl-Str. 3, A-6020 Innsbruck, \\ Austria. Tel: +43-512-507-3504; Fax: +43-512-507-2872; \\ E-mail: Adam.Csordas@uibk.ac.at
}

Received 3.2.00; revised 3.5.00; accepted 11.5.00

Edited by A Finazzi-Agrò

\begin{abstract}
Resveratrol (3,5,4'-trihydroxy-trans-stilbene), in the concentration range of $20 \mu \mathrm{M}$ and above, induced arrest in the Sphase and apoptosis in the T cell-derived T-ALL lymphocytic leukemia cell line $\mathrm{CEM}-\mathrm{C} 7 \mathrm{H} 2$ which is deficient in functional p53 and p16. Expression of transgenic p16/INK4A, which causes arrest in G0/G1, markedly reduced the percentage of apoptotic cells. Antagonist antibodies to Fas or FasL, or constitutive expression of crmA did not diminish the extent of resveratrol-induced apoptosis. Furthermore, a caspase-8negative, Fas-resistant Jurkat cell line was sensitive to resveratrol-induced apoptosis which could be strongly inhibited in the Jurkat as well as in the CEM cell line by zVAD-fmk and z-IETD-fmk. The almost complete inhibition by zIETD-fmk and the lack of inhibition by crmA suggested caspase- 6 to be the essential initiator caspase. Western blots revealed the massive conversion of procaspase- 6 to its active form, while caspase-3 and caspase-2 were proteolytically activated to a much lesser extent. Cell Death and Differentiation (2000) 7, 834-842.
\end{abstract}

Keywords: resveratrol; apoptosis; $\mathrm{CEM}-\mathrm{C} 7 \mathrm{H} 2$ leukemia cells; caspase; crmA; Fas

Abbreviations: Fas, APO-1/CD95; FasL, Fas ligand; rsFasL, recombinant soluble FasL; FACS, fluorescence activated cell sorter; FITC, fluorescein isothiocyanate; PBS, phosphate buffered saline; TBS, TRIS buffered saline; SDS, sodium dodecyl sulfate; crmA, cytokine response modifier A; TNF $\alpha$, tumor necrosis factor $\alpha$

\section{Introduction}

The polyphenolic phytoalexin resveratrol (3,5,4'-trihydroxytrans-stilbene) became well known as a substance present in grapes and wine, especially in red wine, with pronounced pharmacological effects such as inhibition of cyclooxygenase I, antioxidant and anti-inflammatory activity, ${ }^{1}$ inhibition of platelet aggregation and coagulation, ${ }^{2}$ modulation of arachidonic acid metabolism, ${ }^{3}$ lipid metabolism ${ }^{4}$ and inhibition of low density lipoprotein oxidation. ${ }^{5-7}$ Based on these properties, it was suggested that resveratrol is a protective agent against cardiovascular diseases and may be responsible for the socalled French paradox, ${ }^{8,9}$ namely, the lower frequency of myocardial disease in the population of Southern France, in spite of an intake of fat and cholesterol in amounts constituting a risk factor for cardiovascular disease. As a constituent of root extracts of Polygonum cuspidatum ${ }^{10,11}$ resveratrol was used in the Japanese and Chinese folk medicine, and was recently identified as a cyclooxygenase I-inhibiting component of the Peruvian root Cassia quinquangulata. ${ }^{1}$ In assays representing three major stages of carcinogenesis, resveratrol was shown to have anticancerogenic properties. ${ }^{1}$ More recently, antiproliferative and apoptosis-inducing effects of resveratrol were observed in certain tumor cell lines such as HL60 leukemia cells, T47D breast carcinoma cells, ${ }^{12}$ Yoshida $\mathrm{AH}-130$ rat hepatoma cells, ${ }^{13}$ androgen-nonresponsive prostate cancer cells ${ }^{14}$ and in a nontransformed bovine pulmonary artery endothelial cell line. ${ }^{15}$ Interestingly, resveratrol only marginally reduced the survival of unstimulated peripheral blood lymphocytes. ${ }^{12}$ Although the bioassay for cyclooxygenase I inhibition led to purification of the anticancerogenic agent resveratrol, the mechanisms of anticancerogenicity as well as apoptosis triggering of resveratrol remain unknown. Besides inhibition of cyclooxygenase I, recently discovered antiproliferative effects of resveratrol, such as inhibition of ribonucleotide reductase, ${ }^{16}$ inhibition of SV40 DNA replication in CV-1 monkey kidney cells, ${ }^{17}$ and other antiproliferative effects, ${ }^{18-20}$ may also contribute to the anticancerogenic and apoptosis-inducing properties of resveratrol.

In a previous study it was reported that in HL60 leukemia cells and in T47D breast carcinoma cells resveratrolinduced apoptosis was specifically Fas-dependent. ${ }^{12}$ In the $\mathrm{CEM}-\mathrm{C} 7 \mathrm{H} 2$ leukemia cell line of the present study, however, blocking of either Fas or Fas ligand signaling with antagonistic antibodies or constitutive expression of the cowpox serpin crmA had no influence on apoptosis induction by resveratrol. Furthermore, a caspase-8-deficient (Fas- and TNF $\alpha$-resistant) Jurkat mutant cell line was sensitive to apoptosis triggering by resveratrol which - as in $\mathrm{CEM}-\mathrm{C} 7 \mathrm{H} 2$ cells - could be almost completely inhibited by z-IETD-fmk.

Cell cycle analysis revealed that resveratrol causes arrest in the S-phase in a concentration-dependent manner, 
with the arrest occurring at an earlier time point of the Sphase at higher concentrations of resveratrol. Activation of transgenic p16/INK4A caused in CEM-C7H2 cells (which are p16-deficient) an arrest in $\mathrm{G} 0 / \mathrm{G} 1$, and this resulted in a marked reduction in the extent of resveratrol-induced apoptosis. Based on these observations it is suggested that the primary event in resveratrol-induced apoptosis in $\mathrm{CEM}-\mathrm{C} 7 \mathrm{H} 2$ cells is the arrest of DNA replication. The lack of inhibition by $\mathrm{crm} A$ and the strong inhibition by z-IETDfmk was indicative of caspase- 6 being essential for triggering resveratrol-induced apoptosis in $\mathrm{CEM}-\mathrm{C} 7 \mathrm{H} 2$ leukemia cells. Western blotting demonstrated the massive presence of caspase- 6 and detectable amounts of the active forms of caspase- 2 and caspase- 3 in the early phase of resveratrol-induced apoptosis.

\section{Results}

\section{Time- and dose-dependence of resveratrol- induced apoptosis in CEM-C7H2 leukemia cells}

Figure 1 shows that resveratrol is a potent apoptosis inducer in $\mathrm{CEM}-\mathrm{C} 7 \mathrm{H} 2$ cells. Apoptosis detection and quantification was performed by FACS analysis of propidium iodide stained nuclei $^{21}$ (Figure 1A) and annexin $\mathrm{V}$ binding to cells ${ }^{22}$ (Figure 1B). Nuclear DNA fragmentation could be observed with $20 \mu \mathrm{M}$ resveratrol after $48 \mathrm{~h}$ and with $60 \mu \mathrm{M}$ after $24 \mathrm{~h}$. The
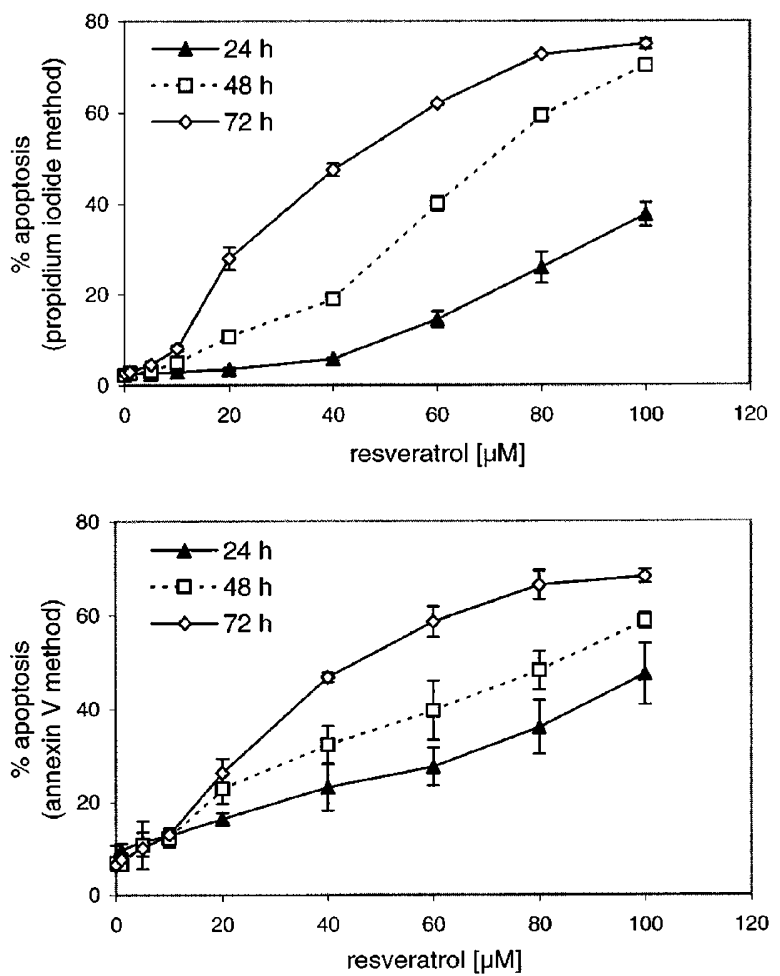

Figure 1 Time- and dose-dependence of resveratrol-induced apoptosis. (A) The percentage of apoptosis was determined by FACS analysis of propidium iodide-stained nuclei of CEM-C7H2 cells. (B) The percentage of apoptosis was determined by FACS analysis of Annexin V binding to CEM-C7H2 cells. Data of a representative experiment are shown as means \pm S.D. of triplicates. Each experiment (in triplicate) was performed at least three times application of $100 \mu \mathrm{M}$ resveratrol caused almost $40 \%$ apoptosis after $24 \mathrm{~h}$ and about $70 \%$ after $48 \mathrm{~h}$ with only a minor further increase at $72 \mathrm{~h}$. The picture in Figure 1B using annexin $\mathrm{V}$ binding for apoptosis detection - was similar, but apoptosis was detected earlier, i.e. $24 \mathrm{~h}$ after application of $40 \mu \mathrm{M}$ resveratrol and $48 \mathrm{~h}$ after application of $20 \mu \mathrm{M}$ resveratrol.

\section{Effects of resveratrol on the cell cycle}

Next we tested the effects of resveratrol on the cell cycle. The cell cycle analysis by FACS (Figure 2), which is based on the same procedure as the apoptosis assay by nuclear propidium iodide fluorescence (see Materials and Methods section), revealed an accumulation of cells in the S-phase. Figure 2 shows the concentration dependence of the cell cycle distribution of CEM-C7H2 cells after $24 \mathrm{~h}$ of incubation at the given concentrations of resveratrol. Accumulation of cells in S-phase can be seen after application of $10 \mu \mathrm{M}$ resveratrol, which keeps increasing with $20 \mu \mathrm{M}$ resveratrol; at $40 \mu \mathrm{M}$, the accumulated cells in early S-phase are very close to the $\mathrm{G} 1$ peak, at $100 \mu \mathrm{M}$ they are so close to the $\mathrm{G} 1$ peak that the $\mathrm{G} 1$ / $\mathrm{S}$ boundary of $\mathrm{S}$-phase cannot be distinguished from $\mathrm{G} 1$. The DNA profiles are, however, difficult to interpret when cell death is initiated in a cell cycle phase other than G0/G1. The question has to be addressed whether Figure 2 shows arrest in the S-phase or rather nuclei with reduced DNA contents after apoptosis induction in G2, which are mistaken for Sphase arrested ones. In support of an arrest in S-phase it should be pointed out: (i) no increase of the G2 peak as a prelude to resveratrol-induced apoptosis was observed in CEM-C7H2 cells; (ii) there is a fairly good agreement in the

\section{resveratrol $/ 24 \mathrm{~h}$}

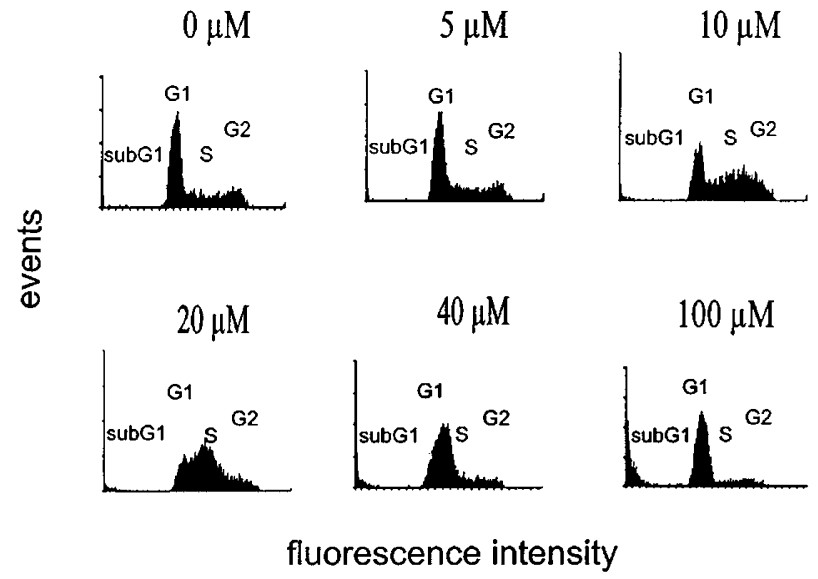

Figure 2 Effects of resveratrol on the cell cycle. Resveratrol treatment of CEM-C7H2 cells results in an accumulation of cells in the S-phase and a decrease of the percentage of cells in G2/M. For cell cycle analysis, propidium iodide-stained nuclei were analyzed by FACS in the same manner as for quantification of apoptosis; however, the fluorescence intensity is plotted on a linear scale. The distribution of $\mathrm{CEM}-\mathrm{C} 7 \mathrm{H} 2$ cells as related to the resveratrol concentration is shown in histograms. The sub-G1 region of apoptotic cells is indicated to the left of the G1 peak. The experiment was performed at least three times 
percentages of apoptotic cells, when comparing the data of propidium iodide fluorescence (in which nuclei in the sub-G1 region are considered as apoptotic) (Figure 1A) with those of annexin $\mathrm{V}$ binding (phosphatidylserine surface exposure) (Figure 1B); (iii) after $24 \mathrm{~h}$ with 10 and $20 \mu \mathrm{M}$ resveratrol the DNA profile shows substantial arrest in S-phase (Figure 2) but a very low level of apoptosis is measured with annexin $\mathrm{V}$; even with 40 and $100 \mu \mathrm{M}$ resveratrol, after $24 \mathrm{~h}$, masses of nuclei are accumulated at the G1/S boundary, but only about 20 and $40 \%$ apoptosis, respectively, is measured by annexin $\mathrm{V}$ binding. Taken together, the data of Figures 1 and 2 suggest that in the course of resveratrol-induced apoptosis, arrest in the S-phase comes first (Figure 2), followed by apoptosis detectable by annexin V (Figure 1B) and subsequently also by propidium iodide (Figure 1A).

\section{Resveratrol-induced apoptosis is abrogated by p16/INK4A-mediated arrest in G0/G1}

Since it was not possible to distinguish between G1 and very early S-phase with the above-described cell cycle analysis, and further, according to our postulate apoptosis is triggered after arrest in the S-phase, we wanted to see whether resveratrol is able to induce apoptosis in cells which have been arrested in G1. For this purpose, we used subclones of CEM-C7H2 (which itself is p16-deficient) stably transfected with the p16/INK4A-gene under the control of the doxycycline 'tet-on' system. In these constructs, the transgenic p16/INK4A gene ${ }^{23}$ can be activated by doxycycline, which causes arrest in G0/G1 without inducing apoptosis. ${ }^{24}$ Resveratrol-induced apoptosis was measured under conditions of activated transgenic $p 16 / I N K 4 A$ gene versus the nonactivated $p 16 /$ INK4A construct, i.e. in the presence and absence of doxycycline in the culture media. If apoptosis by resveratrol is triggered by a specific event which is restricted to the Sphase then apoptosis induction should be prevented by the arrest in G0/G1. Figure 3 shows that this indeed is the case. The induction of the transgenic p16/INK4A gene led to a marked reduction in the percentage of resveratrol-induced apoptosis with a decrease from 38 to $16 \%$. Cells were grown in the presence or absence of $200 \mathrm{ng} / \mathrm{ml}$ doxycycline for $24 \mathrm{~h}$ and then $100 \mu \mathrm{M}$ resveratrol was added for a further $24 \mathrm{~h}$ incubation. Three clones stably transfected with $p 16 / I N K 4 A$ were tested and with all three the partial prevention of resveratrol-induced apoptosis could be observed as a result of overexpression of $p 16 / I N K 4 A$. The CEM-C7H2 cell line which is investigated in the present study is deficient not only in p16 but also in functional p53. Thus, resveratrol-induced apoptosis in this cell line is operative in the absence of functional $\mathrm{p} 53$ and $\mathrm{p} 16$.

\section{Blocking of Fas or the Fas ligand or constitutive expression of crmA does not affect resveratrol- induced apoptosis}

Next we tested whether resveratrol exerts any apoptosis signaling via Fas or Fas ligand. We were prompted to do this in view of a previous study on resveratrol-induced apoptosis in HL-60 cells and T47D breast carcinoma cells ${ }^{12}$ in which resveratrol-induced apoptosis was correlated with upregula-

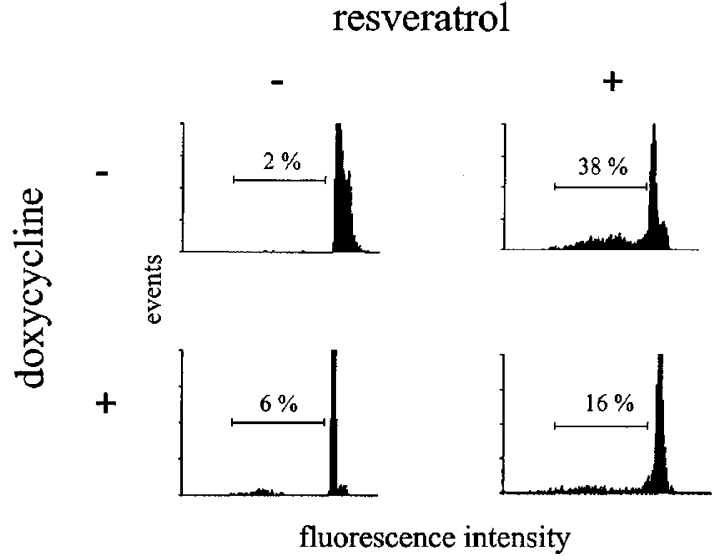

Figure 3 Abrogation of resveratrol-induced apoptosis by expression of transgenic $p 16 / I N K 4 A$. The $\mathrm{C} 7 \mathrm{H} 2^{\text {tetp16 }}$ cell line $1 \mathrm{E} 10$ is a $p 16 / I N K 4 A$ transfected derivative of $\mathrm{C} 7 \mathrm{H} 2-2 \mathrm{C} 8$. The promoter of the transfected $p 16 /$ INK4A becomes activated by doxycycline using the 'tet-on' system. Before addition of resveratrol, cells were treated with doxycycline for $24 \mathrm{~h}$ and subsequent resveratrol treatment $(100 \mu \mathrm{M})$ was for $24 \mathrm{~h}$. Fluorescence intensity is plotted on a logarithmic scale. Because of the logarithmic plot, the $\mathrm{G} 1$ and $\mathrm{G} 2$ peaks are very close to each other. The conspicuously highest peak is the G1 peak. Very near to it to the right with some overlap is the G2/M peak. The G2/M peak is highest in control cells treated neither with resveratrol nor with doxycycline (p16-negative condition without apoptosis inducer). To the left of the G1 peak is the sub-G1 peak representative of apoptotic cells. The percentage of cells in this sub-G1 peak is indicated with numbers in the four panels of the graph. A representative experiment is shown. Experiments were performed at least three times. A similar partial prevention of resveratrolinduced apoptosis was also observed with the other two p16/INK4Atransfected cell lines 1D2 and 6E2

tion of surface expression of Fas and Fas ligand and was sensitive to inhibitory antibodies against Fas or FasL. Figure 4A shows, however, that in CEM-C7H2 leukemia cells, blocking of either Fas or Fas ligand with antagonistic mabs (ZB-4, NOK-1) did not diminish the extent of resveratrolinduced apoptosis, which thus in this cell line has to take place without direct interaction between Fas and the Fas ligand. We also measured the expression levels of Fas and Fas ligand after incubation with $100 \mu \mathrm{M}$ resveratrol for $24 \mathrm{~h}$ and observed unchanged levels (Figure 4B). Thus, in CEM$\mathrm{C} 7 \mathrm{H} 2$ leukemia cells the mechanism of resveratrol-induced apoptosis involves neither the upregulation of Fas ligand or Fas nor the activation of Fas by Fas ligand.

To confirm further the lack of involvement of the Fasreceptor-complex in resveratrol-induced apoptosis, we tested the effect of the cowpox serpin crmA (which blocks Fas- and TNF $\alpha$-mediated apoptosis) in stably transfected CEM-C7H2 cells which constitutively express crmA. ${ }^{25}$ Figure 5 shows that in this cell line, $\mathrm{CH}-11$, an agonistic antibody for Fas, is unable to induce apoptosis, whereas resveratrol-induced apoptosis occurs to the same extent as in the parental cell line. CrmA is an inhibitor of group I (i.e. of caspase-1, caspase-4 and caspase-5) and group III caspases with the exception of caspase- 6 (i.e. of caspase8 , caspase-9 and caspase-10). ${ }^{26-28}$ Thus, with the exception of caspase-6, these caspases cannot play an essential role in resveratrol-induced apoptosis in CEM$\mathrm{C} 7 \mathrm{H} 2$ cells. 

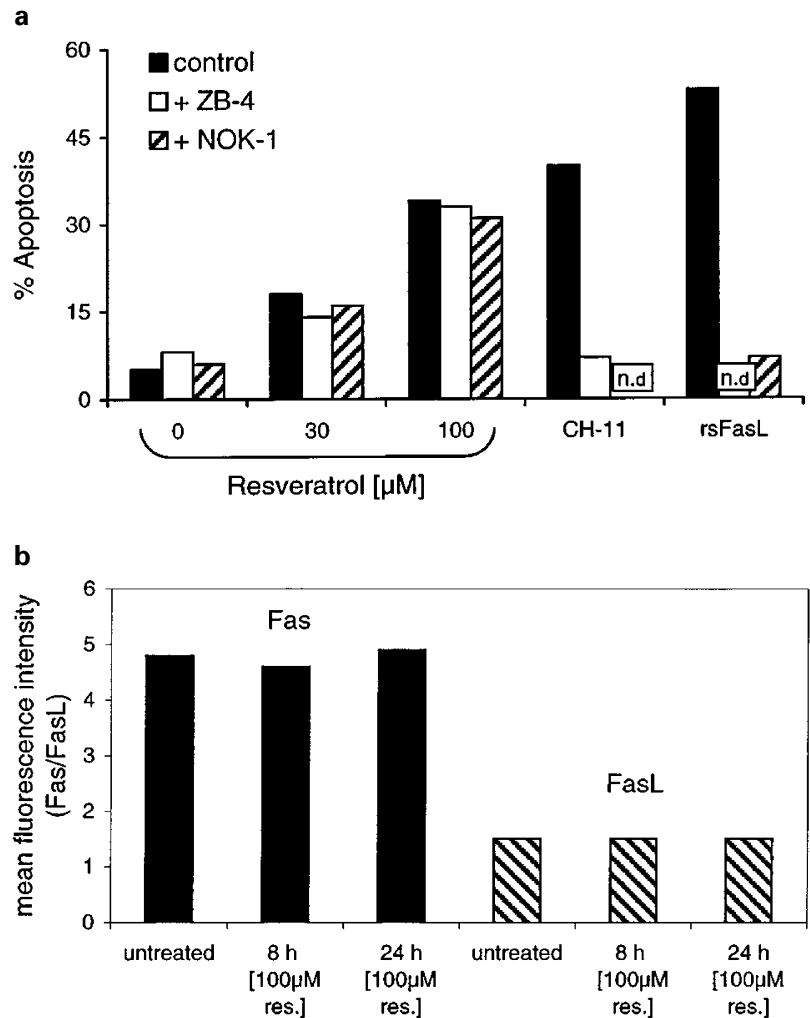

Figure 4 Resveratrol-induced apoptosis is insensitive to inhibition of Fas/ FasL-mediated apoptosis. (A) Resveratrol-induced apoptosis in CEM-C7H2 cells is not blocked by inhibitory antibodies against Fas (ZB-4) or Fas ligand (NOK-1). There is no significant inhibition of resveratrol-induced apoptosis by the inhibitory antibodies, this is shown at apoptosis induction with 30 and $100 \mu \mathrm{M}$ resveratrol for $48 \mathrm{~h}$. Note that apoptosis induced either by the agonistic antibody $\mathrm{CH}-11$ or by the recombinant soluble Fas ligand rsFasL is completely blocked by ZB-4 or NOK-1 $(5 \mu \mathrm{g} / \mathrm{ml}$ each). A representative experiment is shown. (B) For detection of surface Fas and FasL expression, FITC-labeled murine anti-human Fas (clone UB2, Immunotech, Marseille, France) and FITC-labeled anti-human FasL (clone H11, Alexis, Läufelfingen, Switzerland) were used. Briefly, $0.5 \times 10^{6}$ cells were stained with the respective specific mabs $(1 \mu \mathrm{g})$ or an isotype-matched negative control mab for $30 \mathrm{~min}$ at $4^{\circ} \mathrm{C}$, washed and immediately analyzed by flow cytometry. A representative experiment is shown. Mean fluorescence intensity is the quotient of specific anti Fas/FasL fluorescence and the fluorescence of an unspecific isotype control. Under the conditions of resveratrol-induced apoptosis, there is no change in the level of either Fas or Fas ligand; (n.d., not done)

\section{A caspase-8-negative Jurkat cell line is sensitive to resveratrol-induced apoptosis}

We also tested a caspase-8-negative mutant Jurkat cell line, which expresses neither caspase-8a nor caspase $8 b,{ }^{29}$ for sensitivity to resveratrol-induced apoptosis. Figure 6 shows that this caspase-8-negative Jurkat mutant cell line is resistant to Fas apoptosis but sensitive to resveratrol-induced apoptosis. Thus, in the investigated CEM and Jurkat cell lines the triggering of apoptosis by resveratrol occurred without the participation of FasL, Fas and caspase-8. Moreover, in the Jurkat cell line (Figure 6) as well as in the CEM cell line (Figure 7) resveratrol-induced apoptosis was inhibited by z-IETD-fmk, which is consistent with an essential role of caspase- 6 in apoptosis induction in both cell lines.

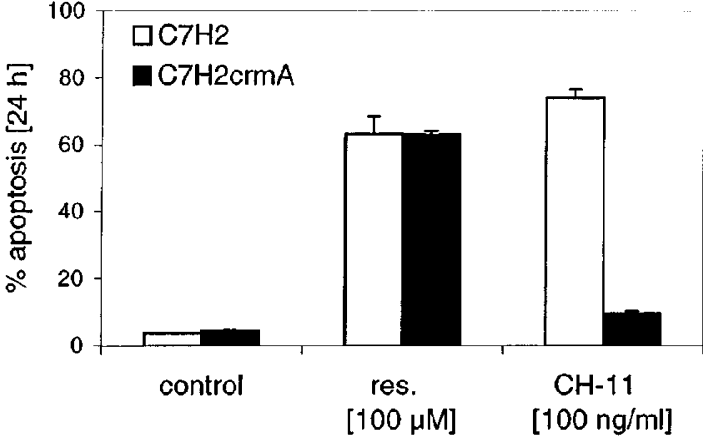

Figure 5 Resveratrol-induced apoptosis is insensitive to crmA. Resveratrolinduced apoptosis $(100 \mu \mathrm{M})$ is not inhibited in the constitutively $\mathrm{crmA}$ expressing cell line $\mathrm{C} 7 \mathrm{H} 2^{\mathrm{CrmA}}-2 \mathrm{E} 8$. Note the almost complete inhibition of Fas-induced apoptosis (agonistic anti-Fas mab CH-11, $100 \mathrm{ng} / \mathrm{ml}$ ) and at the same time the complete lack of effect on resveratrol-induced apoptosis. Means \pm S.D. of a representative experiment, performed in triplicate, are shown

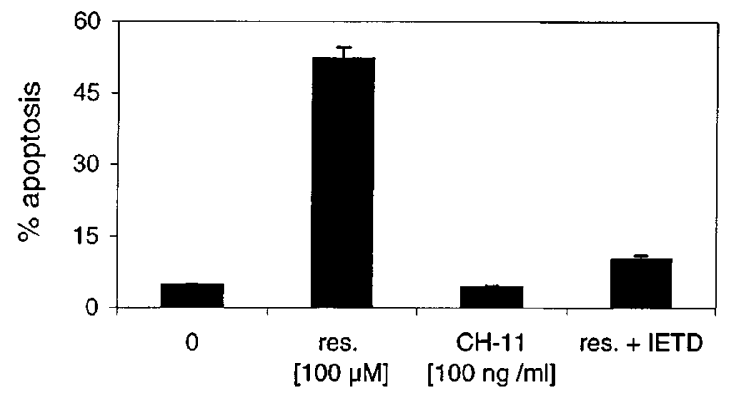

Figure 6 Resveratrol induces apoptosis in the absence of caspase-8. The caspase-8-negative mutant Jurkat cell $\operatorname{line}^{27}$ is resistant to apoptosis induction by the agonistic Fas mab $\mathrm{CH}-11$ but sensitive to resveratrol; zIETD-fmk inhibits resveratrol-induced apoptosis in the caspase-8 deficient Jurkat cells. Apoptosis induction was for $24 \mathrm{~h}$. Means \pm S.D. of a representative experiment, performed in triplicate, are shown

\section{Sensitivity to inhibitory peptides and detection of caspases by immunoblotting}

In order to get more information on the pathway of resveratrolinduced apoptosis in $\mathrm{CEM}-\mathrm{C} 7 \mathrm{H} 2$ cells, various peptide inhibitors of caspases were tested. Figure 7 shows the results of these experiments. z-VAD-fmk, a general caspase inhibitor (but a weak inhibitor of caspase-2 ${ }^{26,27}$ ) and z-IETDfmk, an inhibitor of group III caspases (caspases-6, -8, -9 and $-10)^{26}$ proved to be the two most effective inhibitors of resveratrol-induced apoptosis. The other caspase inhibitors tested, namely, z-YVAD-fmk, a less efficient inhibitor of group III caspases, ${ }^{26} z$-VEID-fmk, an inhibitor with some preference for caspase- $6^{30}$ and z-DEVD-fmk, an inhibitor of caspase-3, -7 and $-8^{27}$ exerted partial inhibition of resveratrol-induced apoptosis within the investigated time periods of 24 and $48 \mathrm{~h}$. Since z-IETD-fmk, an inhibitor of caspase- 6 but not of caspase 3, caused almost complete apoptosis inhibition, the activation of caspase- 6 has to occur upstream of and as a prerequisite for the subsequent activation of caspase-3 (DFF45/ICAD-protease). ${ }^{31}$

In order to further test the conclusions of the inhibition experiments, we probed for the presence of the active 


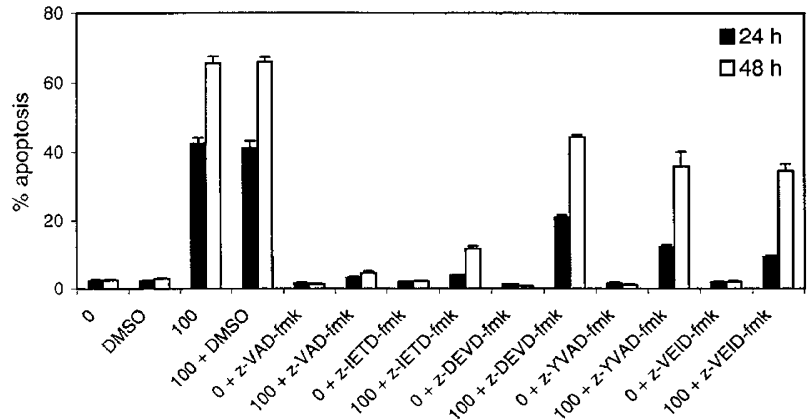

Figure 7 The effects of peptide inhibitors of caspases on resveratrol-induced apoptosis. The percentage of apoptic cells was determined $24 \mathrm{~h}$ (black bars) and $48 \mathrm{~h}$ (open bars) after induction with resveratrol. DMSO was used as solvent for resveratrol as well as for the caspase inhibitor peptides. The numbers 0 and 100 refer to $\mu \mathrm{M}$ resveratrol added. At zero $\mu \mathrm{M}$ resveratrol, $10 \mu \mathrm{l}$ vehicle (DMSO) was added. Data are means \pm S.D. of triplicates of a representative experiment. Experiments (in triplicate) were performed at least three times

forms of several caspases by immunoblot analysis. Figure 8 shows that the active forms of caspase- $6,-3$ and -2 could be detected already 12 and $18 \mathrm{~h}$ after apoptosis induction. While at the time points 12,18 and $24 \mathrm{~h}$ procaspase- 6 (p34) was converted as good as completely to its active form, the level of procaspase-3 (p32) was hardly diminished, only a minor portion of it being proteolytically activated. After $24 \mathrm{~h}$ the active forms of caspase-8 also became detectable. The strong inhibition with z-IETD-fmk (together with the lack of inhibition by $\mathrm{crmA}$ ) indicated that caspase- 6 plays a key role in this apoptosis pathway. The immunoblots of Figure 8 are consistent with this supposition, as caspase- 6 was virtually completely converted to its active form, while the other examined caspases remained to a large extent in their inactive precursor forms even 24 and $48 \mathrm{~h}$ after apoptosis induction.

\section{Discussion}

In the present study it is shown that resveratrol is a potent apoptosis inducer in CEM-C7H2 cells. Until recently the main interest in resveratrol focused on its beneficial effects on the cardiovascular system. It was only in 1997 that canceroprotective effects of resveratrol became known and since then a few reports have emerged on the apoptosis-inducing capacity of resveratrol in tumor cells. ${ }^{12-14}$ Little is known about the cell type-specificity and the mechanism of resveratrol-induced apoptosis. In a previous study it was shown that in the investigated HL60 cell line, and also in T47D breast carcinoma cells, resveratrol-induced apoptosis was strictly Fas/FasL-dependent. ${ }^{12}$ In contrast to this, in the T cell-derived lymphocytic $\mathrm{CEM}-\mathrm{C} 7 \mathrm{H} 2$ cell line investigated in the present study, apoptosis induction by resveratrol took place with undiminished efficiency regardless of whether Fas or Fas ligand was blocked by inhibitory antibodies or whether $\mathrm{crmA}$ was expressed constitutively. It should be emphasized that $\mathrm{crmA}$ is a very potent inhibitor of Fas- and/or TNF $\alpha$-induced apoptosis. $^{32,33}$ Since $c r m A$ is an inhibitor of group I (i.e. of caspase-1, caspase-4 and caspase-5) and group III caspases caspase 2

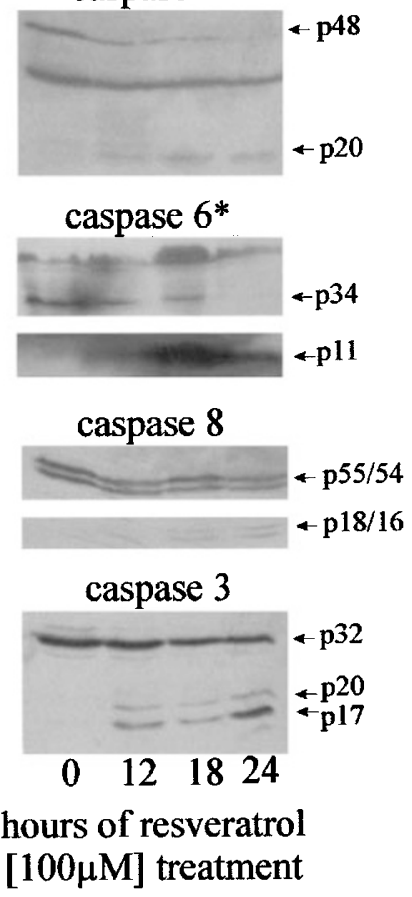

Figure 8 Immunoblot analysis of caspase activation. The Western blots show that the active forms of caspase- 2 , caspase- 6 and caspase- 3 are present before caspase- 8 becomes detectable. Note the virtually complete conversion of procaspase- 6 (p34) to its active form (p11). Apoptosis induction with resveratrol was for 12,18 and $24 \mathrm{~h}$. Lysates of whole cells were applied to SDS-polyacrylamide gel electrophoresis. Western blotting was performed with antibodies against the human caspases as described in Materials and Methods. Because of the low molecular mass of the active form of caspase-6, two membranes were applied in Western blotting. Procaspase-6 (p34) is blotted to the first membrane; the active form of caspase- 6 ( $p 11)$ is revealed on the second membrane

with the exception of caspase-6 (i.e. of caspase-8, -9 and $-10),{ }^{26,27}$ resveratrol-induced apoptosis in CEM-C7H2 cannot be triggered via caspase- 8 or by some deviation from this route via caspase- 9 or caspase-10. This is further underlined by the fact that a Fas- and TNF $\alpha$-resistant caspase-8-negative Jurkat cell line was found to be sensitive for apoptosis induction by resveratrol (Figure 6).

The tight cell cycle dependence of apoptosis sensitivity - with its abrogation by $16 /$ INK $4 A$-mediated arrest in G0/ G1 - strongly suggested that it is the nucleus where the primary apoptosis signal is produced by resveratrol. Resveratrol caused arrest of the cell cycle in the S-phase and cell cycle analysis revealed that the higher the concentration of resveratrol, the earlier is the point in Sphase at which cells are arrested. The cell cycle analysis of the present study is based on DNA content, as measured by FACS analysis of propidium iodide stained nuclei. One may argue that the DNA profiles depicted in the histograms of Figure 2 do not represent nuclei of S-phase arrested cells but rather those of apoptotic G2 arrested ones with DNA contents reduced to various extents; if so, the sub-G1 peak would be a gross underestimate in quantifying apoptotic cells. However, the following data of the present 
study appear to be inconsistent with such an interpretation: (i) an increase of the G2 peak as a result of resveratrol treatment was never observed in CEM-C7H2 cells; and arrest in G0/G1 by transgenic p16/INK4A expression protected these cells from resveratrol-induced apoptosis; (ii) the percentages of apoptotic cells determined as the sub-G1 peak of propidium iodide stained nuclei ${ }^{21}$ (Figure 1A) are in good agreement with those determined by annexin $\mathrm{V}$ membrane staining of whole cells ${ }^{22}$ (Figure 1B), with the exception of the earliest time point measured (24 h), as annexin V staining detects apoptosis already at an earlier stage, before the onset of nuclear fragmentation; (iii) a massive arrest in S-phase was observed at the lower resveratrol concentrations of 10 and $20 \mu \mathrm{M}$ after $24 \mathrm{~h}$ (Figure 2) but at the same time very little apoptosis induction was detected with annexin $\mathrm{V}$ staining of whole cells (Figure 1B). It should be further added that, when performing FACS analysis, parallel to nuclear propidium iodide fluorescence we also measured light scattering by the nuclei under investigation. Dot-analysis of propidium iodide fluorescence versus forward light scatter revealed that the apoptotic nuclei appeared to be shrunk - before any DNA loss could be detected by propidium iodide fluorescence analysis - and once DNA fragmentation started they dropped to the sub-G1 peak level without producing a spectrum of intermediate DNA contents indistinguishable from different stages of the S-phase (the data of the light scattering analysis are not shown). From our observations it can be concluded that either at a certain stage of apoptosis, nuclear DNA is very rapidly degraded to reach the DNA content of the sub-G1 region, or/and condensation of the fragmented nuclear DNA causes a sudden drop in its stainability by propidium iodide. According to the applied technique of Nicoletti et al, ${ }^{21}$ propidium staining of nuclei is performed in a hypotonic buffer in the presence of $0.1 \%$ Triton $\mathrm{X}-100$, which results in the rupture of the plasma membrane, the release of small DNA fragments form the nuclei and at the same time a better penetration of nuclei by propidium iodide is enabled.

Thus, our observations are consistent with the interpretation that resveratrol in $\mathrm{CEM}-\mathrm{C} 7 \mathrm{H} 2$ cells causes an arrest in S-phase, which precedes the onset of DNA fragmentation characteristic of later-stage apoptotic cells. It should be also noted that in a Jurkat cell line, resistant to apoptosis induction by resveratrol, we observed arrest in Sphase without subsequent apoptosis induction as a result of resveratol treatment (unpublished observations). In HL60 promyelocytic leukemia cells, an arrest in S-phase occurred in the absence of a G2/M peak at resveratrol concentrations $(30 \mu \mathrm{M})$ which did not induce apoptosis but caused induction of differentiation. ${ }^{34}$ In that study it was also shown that under these conditions of resveratrol treatment the $\mathrm{G} 1$ cell cycle engine remains undisturbed in HL60 cells. $^{34}$ Furthermore, at concentrations which did not induce apoptosis, resveratrol suppressed proliferation of bovine pulmonary artery endothelial cells by perturbing progression through S-phase and G2. ${ }^{15}$

The question arises as to how resveratrol causes arrest in S-phase. It was reported that resveratrol is an inhibitor of ribonucleotid reductase in murine lymphoblastic leukemia cells ${ }^{16}$ and an inhibitor of proliferation in K562 human erythroleukemia cells and P815 murine mastocytoma cells $^{16}$ and of SV40 replication in CV-1 monkey kidney cells. ${ }^{17}$ If such an inhibitory activity holds true for CEM$\mathrm{C} 7 \mathrm{H} 2$ cells as well, it would explain the arrest in S-phase and subsequent induction of apoptosis out of the S-phase. Consistent with our hypothesis is also a report according to which resveratrol is capable of binding to DNA and in the presence of $\mathrm{Cu}^{2+}$ to cleave DNA. ${ }^{35}$ Thus, we would like to suggest that the arrested replication machinery with stalled replication forks provides the primary signal which in certain cell types results in apoptosis induction. However, in the investigated cell line the mechanism cannot be a generic DNA strandbreak-induced apoptosis, as it was shown in our previous studies that strandbreak-induced apoptosis in CEM-C7H2 cells triggered by $\mathrm{X}$-rays ${ }^{36}$ or doxorubicin ${ }^{37}$ caused accumulation of cells and apoptosis in the G2phase of the cell cycle. Nonetheless, it is conceivable that resveratrol-induced apoptosis is triggered by a different type of DNA lesion.

The possibility that resveratrol, a hydrophobic triphenol, partitions into the plasma membrane and leads to an active conformation of a death receptor on the cytosolic side can be disregarded because of the above-mentioned cell cycle dependence of resveratrol sensitivity. For the same reason, a direct effect of resveratrol on the mitochondria also appears unlikely as the primary apoptosis triggering mechanism.

The inhibition experiments with the peptide inhibitors and the constitutively expressed $\mathrm{crmA}$ strongly suggested that caspase- 6 is the essential initiator caspase of the investigated apoptosis pathway (almost complete inhibition by z-IETD-fmk and lack of inhibition by $\mathrm{crmA}$ ). z-IETD-fmk caused this strong inhibition of resveratrol-induced apoptosis not only in CEM-C7H2 cells (Figure 7) but also in the caspase-8-negative mutant Jurkat cell line (Figure 6).

In Figure 8 the immunoblots show the active forms of caspase- 6 and -3 and -2 to be present 12,18 and $24 \mathrm{~h}$ after apoptosis induction. Only a rather small portion of procaspase- 2 and -3 became activated, while a massive conversion of procaspase- 6 to its active form can be seen. As outlined in a recent review, ${ }^{26}$ the activation of caspase- 6 occurs before the activation of caspase- $3,-2$ and -7 . Thus caspase- 6 (lamin A protease) ${ }^{38,39}$ is not only an effector but also a key initiator caspase. ${ }^{28}$ According to this molecular ordering of caspases, ${ }^{26}$ caspase- 6 should be responsible in the investigated apoptosis pathway for the activation of caspase-3 (DFF45/ICAD protease), ${ }^{31}$ which then leads to the observed DNA-fragmentation (propidium iodide assay). Furthermore, caspase-7 and positive feedback loops involving activated caspases ${ }^{40}$ can be expected to participate in resveratrol-induced cell death in $\mathrm{CEM}-\mathrm{C} 7 \mathrm{H} 2$ cells. Here we have shown that the investigated apoptosis pathway is operative without the crmA-sensitive caspases (caspase-1, -4, -5, -8, -9 and -10), is strongly inhibited by zVAD and z-IETD, and massive conversion of procaspase- 6 to its active form occurs,

There are two major sites in the cell from which death signals can be initiated, namely, the various death-inducing signal complexes of the plasma membrane, and the 
apoptosis machinery of the mitochondria. The present study demonstrates that in $\mathrm{CEM}-\mathrm{C} 7 \mathrm{H} 2$ cells resveratrolinduced apoptosis is clearly Fas- and TNF $\alpha$-independent. It remains to be clarified in further investigations whether the apoptosis pathway of resveratrol in this leukemia cell line is linked to a death receptor other than Fas and the TNF $\alpha$ receptor or is, alternatively, entirely independent of the plasma membrane and linked to the mitochondria.

Since resveratrol was reported to be an inhibitor of cyclo-oxygenase $\mathrm{I}^{1}$ and cyclooxygenase $\mathrm{II}^{41}$ and various cyclooxygenase inhibitors can function as cell type-specific apoptosis inducers, we tested sulindac, indomethacin and sulindac sulfide as apoptosis-inducers in $\mathrm{CEM}-\mathrm{C} 7 \mathrm{H} 2$ cells (data not shown). Sulindac $(200 \mu \mathrm{M})$ did not induce any apoptosis, while $100 \mu \mathrm{M}$ indomethacin (which inhibits cyclooxygenase I more effectively than resveratrol) ${ }^{1}$ and $100 \mu \mathrm{M}$ sulindac sulfide were, compared to resveratrol, poor apoptosis inducers (data not shown).

It should also be noted that, based on its structure, resveratrol, a triphenolic stilben, may act as a phytoestrogen. Indeed, it was reported that resveratrol acts as an estrogen agonist ${ }^{42-44}$ or antagonist ${ }^{45}$ and binds to the estrogen receptor. ${ }^{46}$ Thus, we cannot rule out the involvement of a putative receptor in the apoptosisinducing effect of resveratrol.

Our working hypothesis is that it is the inhibition of DNAreplication by which the primary apoptosis-inducing signal of resveratrol arises in $\mathrm{CEM}-\mathrm{C} 7 \mathrm{H} 2$ cells. It remains to be clarified by further studies how this event is linked to activation of caspases. It should also be explored in which other cell lines apoptosis is induced by resveratrol independent of Fas and the TNF $\alpha$-receptor.

With all the caution called for in drawing conclusions from in vitro cell line experiments regarding the responses of cancer cells in vivo, the dietary component resveratrol, based on its selective actions, may be claimed to be of relevance in prevention as well as therapy of cancer. Resveratrol was only marginally toxic to peripheral blood lymphocytes at concentrations which induced apoptosis in HL60 promyelocytic leukemia cells. ${ }^{12}$ The fact that in an HL60 cell line and T47D breast carcinoma cells resveratrol triggered apoptosis via Fas/FasL, ${ }^{12}$ whereas in CEM-C7H2 leukemia cells resveratrol-induced apoptosis is Fas and TNF $\alpha$-independent, shows that in various resveratrolsensitive cell types different pathways of apoptosis induction can be operative. In another study of HL60 cells it was shown that resveratrol - at non-apoptotic concentrations - is a potent differentiation-inducer after causing arrest in S-phase. ${ }^{34}$ Resveratrol protected K562 erythroleukemia cells against oxidative stress-induced apoptosis as well as against certain other unrelated types of apoptosis, such as apoptosis induced by cisplatin, TGF $\beta 1$ or 5-hydroxyeicosatetraenoic acid. ${ }^{47}$ Interestingly, in that study it was also determined that inhibition of prostaglandin synthesis was correlated with the observed anti-apoptotic effects of resveratrol in K562 leukemia cells. This appears to be in utter contradiction to investigations with other cell types in which the inhibition of prostaglandin biosynthesis was correlated with pro-apoptotic effects of various drugs; for instance, cyclooxygenase II expression made intestinal epithelial cells refractory to butyrate-induced apoptosis, and inhibition of cyclooxygenase II made them sensitive. ${ }^{48}$

Since tumor cells develop strategies to escape Fasmediated apoptosis, the cell type-specific triggering of Fasindependent apoptosis in a p53- and p16- negative background is a desirable property of a potential new therapeutic agent. ${ }^{49-51}$ In the present study we have shown that in $\mathrm{CEM}-\mathrm{C} 7 \mathrm{H} 2$ lymphocytic leukemia cells resveratrol triggered arrest in the S-phase and subsequently Fas-independent apoptosis in the absence of functional p53 and p16 genes. A recent study, however, reported that resveratrol-induced apoptosis occurred only in wild-type p53, but not in p53-deficient mouse fibroblasts. ${ }^{52}$ These seemingly contradictory reports of studies on resveratrol performed with different cell types stand in need of explanation. In several previous studies with other apoptosis inducers, it was also observed that the p53 dependence of apoptosis pathways can be strongly cell type-specific. ${ }^{53,54}$ The delicate balance between oxidant/ antioxidant properties of a given compound might explain its pro- as well as anti-apoptotic effects. Thus, the cell type specificity of redox micro-environments in different cell types may be decisive for an oxidant or anti-oxidant effect of resveratrol. Further, such differences in the redox status could determine the impact of prostaglandin synthesis on the balance between apoptosis/survival or apoptosis/ differentiation in a given cell type. Whatever the mechanism behind the cell type specificity of resveratrol, in its contrasting effects lies its potential to be a highly selective drug as differentiation- or apoptosis-inducer against certain types of tumors.

\section{Materials and Methods}

\section{Materials}

Resveratrol was provided under a Material Transfer Agreement by Pharmascience Inc. (Montreal, Quebec, Canada). Stock solution $(100 \mathrm{mM})$ of resveratrol was prepared in DMSO and kept at $-20^{\circ} \mathrm{C}$. Inhibitory peptides: benzyloxycarbonyl-Val-Ala-Asp-fluoromethylketone (z-VAD-fmk), benzyloxycarbonyl-Asp-Glu-Val-Asp-fluoromethylketone (z-DEVD-fmk), benzyloxycarbonyl-lle-Glu-Thr-Asp-fluoromethylketone (z-IETD-fmk), benzyloxycarbonyl-Tyr-Val-Ala-Asp-fluoromethylketone (z-YVAD-fmk) and benzyloxycarbonyl-Val-Glu-lle-Aspfluoromethylketone (z-VEID-fmk) were obtained from Enzyme Systems Products, (Dublin, CA, USA) and kept as $10 \mathrm{mM}$ stock solutions in DMSO at $-20^{\circ} \mathrm{C}$. The agonistic Fas mab $\mathrm{CH}-11$ (mouse $\operatorname{lgM}$ ) and the antagonistic Fas mab Z-B4 (mouse IgG1) were from Immunotech (Marseille, France); the antagonistic FasL mab NOK-1 (mouse IgG1) was from Pharmingen (San Diego, CA, USA); rsFasL was from Alexis (Läufelfingen, Switzerland). TNF $\alpha$ was from Eubio (Vienna, Austria).

\section{Cell lines and culture conditions}

CEM-C $7 \mathrm{H} 2^{55}$ is a glucocorticoid-sensitive subline of CCRF-CEMC7. ${ }^{56} \mathrm{C} 7 \mathrm{H} 2-2 \mathrm{C} 8$ is a subclone of the $\mathrm{CEM}-\mathrm{C} 7 \mathrm{H} 2$ cell line stably transfected with the reverse tetracycline-controlled transcriptional transactivator, rtTA. ${ }^{57,58}$ The cell lines $\mathrm{C} 7 \mathrm{H} 2^{\text {tetp16 }}-1 \mathrm{E} 10,6 \mathrm{E} 2$, and $1 \mathrm{D} 2^{24}$ are derivatives of the $\mathrm{C} 7 \mathrm{H} 2-2 \mathrm{C} 8$ cell line that are stably 
transfected with $p 16 / I N K 4 A$ under the control of the tetracyclinesensitive transcriptional transactivator. Expression is controlled by rtTA, i.e., it is induced by tetracycline ('tet-on' system). For induction of p16/INK4A, $200 \mathrm{ng} / \mathrm{ml}$ doxycycline was added to the media $24 \mathrm{~h}$ prior to treatment with the apoptosis inducer. The generation of $\mathrm{C} 7 \mathrm{H} 2$ sublines stably transfected with constructs allowing constitutive expression of the cowpox virus caspase inhibitor crmA (cell lines $\left.\mathrm{C} 7 \mathrm{H} 2^{\mathrm{crmA}}-2 \mathrm{E} 8,2 \mathrm{G} 10,2 \mathrm{H} 10\right)^{25}$ has been described. The caspase-8negative mutant Jurkat cell line was a generous gift of Dr. Peter Juo, Department of Cell Biology, Harvard Medical School; it was isolated from the Fas apoptosis-sensitive Jurkat subclone A3 after three cycles of exposure to the frameshifting mutagen ICR $191 .{ }^{29}$ For all the cell lines investigated, tissue culture medium was RPMI 1640 supplemented with $10 \%$ fetal bovine serum (HyClone, Logan, UT, USA), $100 \mathrm{U} / \mathrm{ml}$ penicillin, $100 \mu \mathrm{g} / \mathrm{ml}$ streptomycin and $2 \mathrm{mM}$ L-glutamine. All cell lines were grown in $5 \% \mathrm{CO}_{2}$ and saturated humidity at $37^{\circ} \mathrm{C}$.

\section{Apoptosis assay}

Detection and/or quantification of apoptosis was performed by FACS analysis of nuclear propidium iodide fluorescence ${ }^{21}$ or annexin V-FITC binding to cells. ${ }^{22}$ The dose- and time-dependence of resveratrolinduced apoptosis is shown with the propidium iodide (Figure 1A) as well as the annexin $V$ methods (Figure $1 \mathrm{~B}$ ). In all other figures of this study the percentage of apoptosis was determined by FACS analysis of propidium iodide stained nuclei as described previously. ${ }^{21,59}$ Briefly, $5 \times 10^{5}$ cells were permeabilized and stained with $750 \mu \mathrm{l}$ propidium iodide $(50 \mu \mathrm{g} / \mathrm{ml}$ in $0.1 \%$ Triton X-100/0.1\% sodium citrate) and subjected to apoptosis analysis in a FACScan (FL-2 channel, Becton Dickinson, San Jose, CA, USA; equipped with an argon laser). Based on propidium iodide staining, cells in the sub-G1 marker window were considered to be apoptotic. Parallel to nuclear propidium iodide fluorescence, light scattering was also measured. According to the light scattering analysis, apoptotic nuclei are recognized as being smaller (lower forward scatter values) and more granulated (higher sideward scatter values). Cell debris and small particles were excluded from the analysis by forward/sideward scatter criteria as described. ${ }^{60}$ Annexin $\mathrm{V}$ binding ${ }^{33}$ was determined using the TACS Annexin V-FITC kit (Trevigen, Gaithersburg, MD, USA), as described by the manufacturer. Approximately $2.5 \times 10^{5}$ cells were washed, incubated with FITC-labeled annexin V and analyzed on a FACScan. Annexin $V$ does not bind to viable cells but binds to apoptotic cells already at an early stage of apoptosis.

\section{Cell cycle analysis}

For cell cycle analyses, the propidium iodide method of Nicoletti et $a l,{ }^{21}$ was used as described above for determination of apoptosis by propidium iodide staining of nuclei, except that the fluorescence intensity was plotted on a linear rather than a logarithmic scale.

\section{Western blotting}

For immunoblotting, cells were washed in PBS, suspended in sample

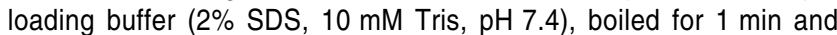
sonicated. Equal protein amounts of cell lysates were separated in SDS-polyacrylamide gels and transferred onto nitrocellulose membranes (Schleicher \& Schuell, Dassel, Germany). After blocking nonspecific binding sites for $1 \mathrm{~h}$ with $5 \%$ nonfat milk in TTBS (TBS with $0.1 \%$ Tween 20 ), the membranes were incubated for $2 \mathrm{~h}$ at room temperature with antibodies against caspase-2, caspase-3, caspase- 6 (Pharmingen, San Diego, CA, USA) or caspase-8 (Upstate Biotechnology, Lake Placid, NY, USA). The antibodies were dissolved in blocking buffer (TTBS with 5\% nonfat milk). The membranes were washed three times in TTBS and incubated for $1 \mathrm{~h}$ with horseradish peroxidase-conjugated sheep anti-mouse or donkey anti-rabbit antibodies (Amersham, Les Ulis, France), after which they were washed again three times in TTBS. The immunoblots were revealed using an enhanced chemiluminescence detection kit (ECL Western blotting detection reagents RPN 2106) (Amersham Pharmacia Biotech, Buckinghamshire, UK).

\section{Acknowledgements}

This work was supported by grants from the Austrian Science Fund (SFBF204), the Österreichische Krebshilfe-Krebsgesellschaft Tirol and the Province of Tyrol. We are indebted to Ms. Rajam Csordas-lyer for critical reading and editorial assistance.

\section{References}

1. Jang M, Cai L, Udeani GO, Slowing KV, Thomas CF, Beecher CWW, Fong HHS, Farnsworth NR, Kinghorn AD, Mehta RG, Moon RC and Pezzuto JM (1997) Cancer chemopreventive activity of resveratrol, a natural product derived from grapes. Science 275: 218-220

2. Pace-Asciak CR, Hahn S, Diamandis EP, Soleas G and Goldberg DM (1995) The red wine phenolics trans-resveratrol and quercetin block human platelet aggregation and eicosanoid synthesis: Implications for protection against coronary heart disease. Clin. Chim. Acta 235: 207-219

3. Kimura Y, Okuda $\mathrm{H}$ and Arichi S (1985) Effects of stilbenes on arachidonate metabolism in leukocytes. Biochim. Biophys. Acta 834: 275-278

4. Arichi H, Kimura Y, Okuda H, Baba K, Kozawa M and Arichi S (1982) Effects of stilbene components of the roots of Polygonum cuspidatum Sieb. etZucc. on lipid metabolism. Chem. Pharm. Bull. (Tokyo) 30: 1766-1770

5. Frankel EN, Waterhouse AL and Kinsella JE (1993) Inhibition of human LDL oxidation by resveratrol. Lancet 341: 1103-1104

6. Frankel EN, Kanner J, German JB, Parks E and Kinsella JE (1993) Inhibition of oxidation of human low-density lipoprotein by phenolic substances in red wine. Lancet 341: $454-457$

7. Kerry NL and Abbey M (1997) Red wine and fractionated phenolic compounds prepared from red wine inhibit low density lipoprotein oxidation in vitro. Atherosclerosis 135: 93-102

8. Renaud S and de Lorgeril M (1992) Wine, alcohol, platelets, and the French paradox for coronary heart disease. Lancet 339: 1523-1526

9. Soleas GJ, Diamandis EP and Goldberg DM (1997) Resveratrol: a molecule whose time has come? And gone? Clin. Biochem. 30: 91-113

10. Nonomura S, Kanagawa $\mathrm{H}$ and Makimoto A (1963) Chemical constituents of polygonaceous plants. I. Studies on the components of KO-jo-kon. (Polygonum cuspidatum Sieb. et Zucc.). Yakugaku Zasshi 83: 988-990

11. Kubo M, Kimura Y, Shin H, Haneda T, Tani T and Namba K (1981) Studies on the antifungal substance of crude drug (II). On the roots of Polygonum cuspidatum Sieb. et Zucc. (Polygonaceae). Shoyakugaku Zasshi 35: 58-61

12. Clement MV, Hirpara JL, Chawdhury SH and Pervaiz S (1998) Chemopreventive agent resveratrol, a natural product derived from grapes triggers CD95 signalingdependent apoptosis in human tumor cells. Blood 92: 996-1002

13. Carbó N, Costelli P, Baccino FM, López-Soriano FJ and Argilés JM (1999) Resveratrol, a natural product present in wine, decreases tumour growth in a rat tumour model. Biochem. Biophys. Res. Commun. 254: 739-743

14. Hsieh TC and Wu JM (1999) Differential effects on growth, cell cycle arrest, and induction of apoptosis by resveratrol in human prostate cancer cell lines. Exp. Cell Res. 249: 109-115

15. Hsieh TC, Juan G, Darzynkiewicz Z and Wu JM (1999) Resveratrol increases nitric oxide synthase, induces accumulation of p53 and p21 WAF1/CIP1 , and suppresses cultured bovine pulmonary artery endothelial cell proliferation by perturbing progression through $S$ and $\mathrm{G}_{2}$. Cancer Res. 59: 2596-2601 
16. Fontecave M, Lepoivre M, Elleingand E, Gerez C and Guittet O (1998) Resveratrol, a remarkable inhibitor of ribonucleotide reductase. FEBS Lett. 421: $277-279$

17. Sun NJ, Woo SH, Cassady JM and Snapka RM (1998) DNA polymerase and topoisomerase II inhibitors from Psoralea corylifolia. J. Nat. Prod. 61: 362-366

18. Fang $N$ and Casida JE (1998) Anticancer action of cubé insecticide: correlation for rotenoid constituents between inhibition of NADH:ubiquinone oxidoreductase and induced ornithine decarboxylase activities. Proc. Natl. Acad. Sci. USA 95: $3380-3384$

19. Mgbonyebi OP, Russo J and Russo IH (1998) Anitproliferative effect of synthetic resveratrol on human breast epithelial cells. Int. J. Oncol. 12: 865-869

20. EIAttar TM and Virji AS (1999) Modulating effect of resveratrol and quercetin on oral cancer cell growth and proliferation. Anticancer Drugs 10: 187-193

21. Nicoletti I, Migliorati G, Pagliacci MC, Grignani F and Riccardi C (1991) A rapid and simple method for measuring thymocyte apoptosis by propidium iodide staining and flow cytometry. J. Immunol. Methods 139: 271-279

22. Martin SJ, Reutelingsperger CPM and Green DR (1996) Annexin V: a specific probe for apoptotic cells. In Techniques in apoptosis Cotter TG and Martin SJ eds (London: Portland Press Ltd) pp. 107-120

23. Sharpless NE and DePinho RA (1999) The INK4A/ARF locus and its two gene products. Curr. Opin. Genetics Dev. 9: 22-30

24. Bernhard D, Ausserlechner MJ, Tonko M, Löffler M, Hartmann BL, Csordas A and Kofler R (1999) Apoptosis induced by the histone deacetylase inhibitor sodium butyrate in human leukemic lymphoblasts. FASEB J. 13: 1991-2001

25. Geley S, Hartmann BL, Kapelari K, Egle A, Villunger A, Heidacher D, Greil R, Auer $B$ and Kofler $R$ (1997) The interleukin $1 \beta$-converting enzyme inhibitor $C r m A$ prevents Apo/Fas- but not glucocortoid-induced poly(ADP-ribose) polymerase cleavage and apoptosis in lymphoblastic leukemia cells. FEBS Lett. 402:36-40

26. Garcia-Calvo M, Peterson EP, Leiting B, Ruel R, Nicholson DW and Thornberry NA (1998) Inhibition of human caspases by peptide-based and macromolecular inhibitors. J. Biol. Chem. 273: 32608-32613

27. Ekert PG, Silke J and Vaux DL (1999) Caspase inhibitors. Cell Death Differ. 6: $1081-1086$.

28. Nicholson DW (1999) Caspase structure, proteolytic substrates, and function during apoptotic cell death. Cell Death Differ. 6: 1028-1042

29. Juo P, Kuo CJ, Yuan J and Blenis J (1998) Essential requirement for caspase-8/ FLICE in the initiation of the Fas-induced apoptotic cascade. Curr. Biol. 8: 1001 1008

30. Hirata H, Takahashi A, Kobayashi S, Yonehara S, Sawai H, Okazaki T, Yamamoto K and Sasada M (1998) Caspases are activated in a branched protease cascade and control distinct downstream processes in Fas-induced apoptosis. J. Exp. Med. 187: 587-600

31. Enari M, Sakahira H, Yokoyama H, Okawa K, Iwamatsu A and Nagata S (1998) A caspase-activated DNase that degrades DNA during apoptosis, and its inhibitor ICAD. Nature 391: 43-50

32. Tewari M and Dixit VM (1995) Fas- and tumor necrosis factor-induced apoptosis is inhibited by the poxvirus crmA gene product. J. Biol. Chem. 270: 3255-3260

33. Miura M, Friedlander RM and Yuan J (1995) Tumor necrosis factor-induced apoptosis is mediated by a CrmA-sensitive cell death pathway. Proc. Natl. Acad. Sci. USA 92: 8318-8322

34. Della Ragione F, Cucciolla V, Borriello A, Della Pietra V, Racioppi L, Soldati G, Manna C, Galletti P and Zappia V (1998) Resveratrol arrests the cell division cycle at S/G2 phase transition. Biochem. Biophys. Res. Commun. 250: 53-58

35. Fukuhara K and Miyata N (1998) Resveratrol as a new type of DNA-cleaving agent. Bioorg. Med. Chem. Lett. 8: 3187-3192

36. Strasser-Wozak EM, Hartmann BL, Geley S, Sgonc R, Böck G, Santos AJ, Hattmannstorfer R, Wolf H, Pavelka M and Kofler R (1998) Irradiation induces G2/M cell cycle arrest and apoptosis in p53-deficient lymphoblastic leukemia cells without affecting Bcl-2 and Bax expression. Cell Death Differ. 5: 687-693

37. Villunger A, Egle A, Kos M, Hartmann BL, Geley S, Kofler R and Greil R (1997) Drug-induced apoptosis is associated with enhanced Fas (Apo-1/CD95) ligand expression but occurs independently of Fas (Apo-1/CD95) signaling in human $T$ acute lymphatic leukemia cells. Cancer Res. 57: 3331-3334

38. Takahashi A, Alnemri ES, Lazebnik YA, Fernandes-Alnemri T, Litwack G, Moi RD, Goldman RD, Poirier GG, Kaufmann SH, Earnshaw WC (1996) Cleavage of lamin A by Mch2 $\alpha$ but not CPP32: Multiple interleukin $1 \beta$-converting enzymerelated proteases with distinct substrate recognition properties are active in apoptosis. Proc. Natl. Acad. Sci. USA 93: 8395-8400
39. Orth K, Chinnaiyan AM, Garg M, Froelich CJ and Dixit VM (1996) The CED-3/ ICE-like protease Mch2 is activated during apoptosis and cleaves the death substrate lamin A. J. Biol. Chem. 271: 16443-16446

40. Van de Craen M, Declercq W, Van den brande I, Fiers W and Vandenabeele P (1999) The proteolytic procaspase activation network: an in vitro analysis. Cell Death Differ. 6: 1117-1124

41. Subbaramaiah $\mathrm{K}$, Chung WJ, Michaluart $\mathrm{P}$, Telang N, Tanabe T, Inoue H, Jang M, Pezzuto JM and Dannenberg AJ (1998) Resveratrol inhibits cyclooxygenase2 transcription and activity in phorbol ester-treated human mammary epithelial cells. J. Biol. Chem. 273: 21875-21882

42. Gehm BD, McAndrews JM, Chien PY and Jameson JL (1997) Resveratrol, a polyphenolic compound found in grapes and wine, is an agonist for the estrogen receptor. Proc. Natl. Acad. Sci. USA 94: 14138-14143

43. Stahl S, Chun TY and Gray WG (1998) Phytoestrogens act as estrogen agonists in an estrogen-responsive pituitary cell line. Toxicol. Appl. Pharmacol. 152: 41 48

44. Turner RT, Evans GL, Zhang M, Maran A and Sibonga JD (1999) Is resveratrol an estrogen agonist in growing rats? Endocrinology 140: 50-54

45. Lu R and Serrero G (1999) Resveratrol, a natural product derived from grape, exhibits antiestrogenic activity and inhibits the growth of human breast cancer cells. J. Cell Physiol. 179: 297-304

46. Ashby J, Tinwell H, Pennie W, Brooks AN, Lefevre PA, Beresford N and Sumpter JP (1999) Partial and weak oestrogenicity of the red wine constituent resveratrol: consideration of its superagonist activity in MCF- 7 cells and its suggested cardiovascular protective effects. J. Appl. Toxicol. 19: 39-45

47. Maccarrone M, Lorenzon T, Guerrieri P and Finazzi Agrò A (1999) Resveratrol prevents apoptosis in $\mathrm{K} 562$ cells by inhibiting lipoxygenase and cyclooxygenase activity. Eur. J. Biochem. 265: 27-34

48. Tsujii M and DuBois RN (1995) Alterations in cellular adhesion and apoptosis in epithelial cells overexpressing prostaglandin endoperoxide synthase 2. Cell 83: 493-501

49. Hollstein M, Sidransky D, Vogelstein B and Harris CC (1991) p53 mutations in human cancers. Science 253: $49-53$

50. Levine AJ, Momand J and Finlay CA (1991) The p53 tumour suppressor gene. Nature 351: 453-456

51. Otsuki T, Clark HM, Wellmann A, Jaffe ES and Raffeld M (1995) Involvement of CDKN2(p16 $\left.6^{I N K 4 A} / M T S 1\right)$ and $p 15^{I N K 4 B} / M T S 2$ in human leukemias and lymphomas. Cancer Res. 55: 1436-1440

52. Huang C, Ma WY, Goranson A and Dong Z (1999) Resveratrol suppresses cell transformation and induces apoptosis through a p53-dependent pathway. Carcinogenesis 20: 237-242

53. Midgley CA, Owens B, Briscoe CV, Thomas DB, Lane DP and Hall PA (1995) Coupling between gamma irradiation, $\mathrm{p} 53$ induction and the apoptotic response depends upon cell type in vivo. J. Cell Sci. 108: 1843-1848

54. MacFarlane M, Jones NA, Dive C and Cohen GM (1996) DNA-damaging agents induce both p53-dependent and p53-independent apoptosis in immature thymocytes. Mol. Pharmacol. 50: 900-911

55. Strasser-Wozak EMC, Hattmannstorfer R, Hala M, Hartmann BL, Fiegl M, Geley $S$ and Kofler R (1995) Splice site mutation in the glucocorticoid receptor gene causes resistance to glucocorticoid-induced apoptosis in a human acute leukemic cell line. Cancer Res. 55: 348-353

56. Norman MR and Thompson EB (1977) Characterization of a glucocorticoidsensitive human lymphoid cell line. Cancer Res. 37: 3785-3791

57. Gossen M and Bujard H (1992) Tight control of gene expression in mammalian cells by tetracycline-responsive promoters. Proc. Natl. Acad. Sci. USA 89: $5547-5551$

58. Gossen M, Freundlieb S, Bender G, Müller G, Hillen W and Bujard H (1995) Transcriptional activation by tetracyclines in mammalian cells. Science 268 : $1766-1769$

59. Bernhard D, Löffler M, Hartmann BL, Yoshida M, Kofler R and Csordas A (1999) Interaction between dexamethasone and butyrate in apoptosis induction: nonadditive in thymocytes and synergistic in a T cell-derived leukemia cell line. Cell Death Differ. 6: 609-617

60. Sgonc R and Wick G (1994) Methods for the detection of apoptosis. Int. Arch. Allergy Immunol. 105: 327-332 